\title{
Postoperative transient elevation of serum cancer antigen 125 in non-small cell lung cancer patients
}

\author{
Yiwang $\mathrm{Ye}^{1 *}(\mathrm{~B})$
}

\section{SUMMARY}

OBJECTIVE: The aim of this retrospective study was to investigate the correlation of transiently elevated postoperative serum cancer antigen 125 levels and prognosis in patients with non-small cell lung cancer.

METHODS: A total of 181 non-small cell lung cancer patients with normal levels of preoperative serum cancer antigen 125 were statistically summarized in this study.

RESULTS: Out of the analyzed patients, 22 (12.2\%) showed elevation of serum cancer antigen 125 within one month after surgery. Serum cancer antigen 125 level decreased to normal at three months postoperation. Serum cancer antigen 125 was positively correlated with pro-brain natriuretic peptide in non-small cell lung cancer postoperative patients ( $p=0.00035)$. Univariate analysis did not find significant difference in disease progression survival between those who experienced cancer antigen 125 elevation in the early postoperation and those who did not $(p=0.646)$.

CONCLUSIONS: In conclusion, transient elevation of cancer antigen 125 is associated to pro-brain natriuretic peptide increase after pulmonary surgery in non-small cell lung cancer patients.

KEYWORDS: Carcinoma, non-small-cell lung. CA-125 antigens. Biomarkers. Neoplasms. Natriuretic peptide, brain.

\section{INTRODUCTION}

Cancer antigen 125 (CA-125) is a glycoprotein antigen commonly produced by epithelial serous cells in fetal tissues but in mesothelial cells in adults ${ }^{1}$. It has been used as a clinical tumor marker for prognosis and therapy monitoring in ovarian and breast cancer patients ${ }^{2,3}$. High serum levels of the CA-125 have also been reported in heart failure, nephrotic syndrome, liver cirrhosis, tuberculosis and pelvic inflammatory diseases ${ }^{4-11}$. The CA-125 levels were positively correlated with pro-brain natriuretic peptide (proBNP) in patients with coronary heart disease. Some studies also reported CA-125 as a marker for worse prognosis in lung cancer ${ }^{12-14}$. Preoperative CA-125 measured in serum in operable patients has been suggested as a prognostic factor in NSCLC in some studies ${ }^{15-17}$. Nuńez et al. ${ }^{18}$ reported two cases of elevated serum CA-125 levels in postoperated
NSCLC patients and it regressed spontaneously in three and eight months post-operation. However, no other studies reported this drop in CA-125. In this study, we have systemically investigated the relationship between transient elevation of serum CA-125 status in early postoperative NSCLC patients with clinical data and pro-BNP.

\section{METHODS}

\section{Patients}

This study was approved by the ethics committee of the Peking University Shenzhen Hospital. We enrolled 181 patients with normal levels of serum CA-125, who underwent surgeries from January 2016 to May 2019 in the Thoracic Surgery Department of Peking University Shenzhen Hospital (Shenzhen, China).

\footnotetext{
'Peking University Shenzhen Hospital-Shenzhen, China.

*Corresponding author: yyw.gh|@163.com

Conflicts of interest: the authors declare there are no conflicts of interest. Funding: none.

Received on September 29, 2020. Accepted on November 23, 2020.
} 
Among these patients, 22 of them were found to have elevation of serum CA-125 within one month after operation. We have analyzed clinicopathological features, including age, gender, smoking, history of hypertension, other nonmalignant diseases (heart failure, nephrotic syndrome, liver cirrhosis, tuberculosis, and pelvic inflammatory disease), location, surgical approach, type of resection, operation time, postoperative pleural effusion (in one month after surgery), histological type, classification system stage, pro-BNP, and survival outcomes. We adopted the staging system of the Union for International Cancer Control (UICC), eighth edition, 2018.01. Most of these NSCLC patients underwent lobectomy plus systematic mediastinal lymphadenectomy, while some patients with pure ground-glass opacity (pGGO) less than $1 \mathrm{~cm}$ underwent segmentectomy or wedge resection plus systematic mediastinal lymphadenectomy or mediastinal lymph node sampling.

\section{Initial assessment and follow-up}

Initial evaluation included complete medical history and physical examination, with extra attention to symptoms often associated with lung cancer. Chest computed tomography (CT) scan or positron emission tomography - computed tomography (PET/CT) and laboratory tests were performed, including CA-125 level.

Serum CA-125 was tested half a month before and one month after operation, and the following tests were conducted at three months, six months, and then every year after operation. All tests were performed according to the manufacturer's instructions. The cutoff point for CA-125 was $30 \mathrm{ng} / \mathrm{mL}$, as determined by the manufacturer (Abbott, ARCHITECT i40000).

Pro-BNP was tested half a month before operation and within one day after surgery, and repeated one month after operation. All tests were performed according to the manufacturer's instructions. The cutoff point for pro-BNP, as determined by the manufacturer, was $125 \mathrm{pg} / \mathrm{mL}$.

Recurrences were evaluated by physical examination, CT, PET/CT, magnetic resonance imaging and/or histological biopsy.

\section{Statistical analyses}

Statistical analyses were carried out using the software SPSS 25.0 (IBM Corp, Armonk, NY, USA). The statistical endpoint of analyses was disease-free survival (DFS) from the date of surgery. Group distributions for each clinicopathological trait were compared using the two-tailed Fisher's exact procedure and the $\chi^{2}$ test. Univariate analysis was performed using the Cox proportional hazards model. Statistical significance was defined as $\mathrm{p}<0.05$.

\section{RESULTS}

\section{Patient characteristics}

The patient characteristics are given in Table 1. All 181 patients were diagnosed with NSCLC and have normal preoperative serum CA-125 level. The average age was 55.5 years and the subjects were predominately male (female to male ratio 84:97).

Table 1. Baseline characteristics of non-small lung cancer patients with normal preoperation cancer antigen 125 level.

\begin{tabular}{|c|c|c|}
\hline & $\mathrm{n}$ \\
\hline \multirow{2}{*}{ Age (years) } & $<70$ & 166 \\
\hline & $\geq 70$ & 15 \\
\hline \multirow{2}{*}{ Gender } & Male & 84 \\
\hline & Female & 97 \\
\hline \multirow{2}{*}{ Smoking } & Yes & 51 \\
\hline & No & 130 \\
\hline \multirow{2}{*}{$\begin{array}{l}\text { Operation time } \\
\text { (hours) }\end{array}$} & $<3$ & 148 \\
\hline & $\geq 3$ & 33 \\
\hline \multirow[b]{2}{*}{ Surgical approach } & Thoracotomy & 14 \\
\hline & $\begin{array}{l}\text { Video-assisted } \\
\text { thoracic surgery }\end{array}$ & 167 \\
\hline \multirow{2}{*}{ Type of resection } & $\begin{array}{l}\text { Lobectomy/ } \\
\text { pneumonectomy }\end{array}$ & 142 \\
\hline & $\begin{array}{l}\text { Segmentectomy/ } \\
\text { wedge resection }\end{array}$ & 39 \\
\hline \multirow{2}{*}{ Tumor location } & Upper lobe & 107 \\
\hline & Middle lobe/low lobe & 74 \\
\hline \multirow{2}{*}{ Hypertension } & Yes & 37 \\
\hline & No & 144 \\
\hline \multirow{2}{*}{$\begin{array}{l}\text { Postoperative } \\
\text { pleural effusion }\end{array}$} & Yes & 27 \\
\hline & No & 154 \\
\hline \multirow{2}{*}{ Stage } & 1 & 112 \\
\hline & $\|/\| I \|$ & 69 \\
\hline \multirow[b]{2}{*}{ Histology } & Adenocarcinoma & 137 \\
\hline & $\begin{array}{c}\text { Squamous cell } \\
\text { carcinoma/other type }\end{array}$ & 44 \\
\hline \multirow{4}{*}{$\begin{array}{l}\text { Other nonmalignant } \\
\text { diseases }\end{array}$} & Heart failure & 0 \\
\hline & Nephrotic syndrome & 0 \\
\hline & Liver cirrhosis & 0 \\
\hline & Tuberculosis & 5 \\
\hline \multirow{2}{*}{$\begin{array}{l}\text { Pro-brain natriuretic } \\
\text { peptide elevated } \\
\text { postoperatively }\end{array}$} & Yes & 38 \\
\hline & No & 143 \\
\hline
\end{tabular}


A total of 112 patients (61.9\%) were classified as stage I, and other 69 patients (30.1\%) as stage II or III. A total of 137 cases were of lung adenocarcinoma, and other 44 cases of lung squamous cell carcinoma or other type of NSCLC. Thirty-seven patients had history of hypertension and blood pressure control well before surgery. As for other nonmalignant diseases (heart failure, nephrotic syndrome, liver cirrhosis, tuberculosis, and pelvic inflammatory disease), only 5 patients had history of tuberculosis. Serum pro-BNP levels were in normal range in all 181 patients pre-operatively, and raised above normal level $(>125 \mathrm{pg} / \mathrm{mL})$ in 38 patients within one day after surgery and decreased to normal level in one month follow-up.

\section{Levels of cancer antigen 125}

Levels of serum CA-125 were found to be transiently elevated in one month after surgery in 22 patients $(12.2 \%)$, and it returned to normal level in the follow-up examination after three months (Figure 1A). On the other hand, in the rest of the 159 patients, the levels of CA-125 were found to be normal in three months postoperation.

\section{Transient elevation of serum cancer antigen 125 postoperative and clinical characteristics}

The baseline characteristics of patients were considered, including age, gender, operative time, tumor stage, tumor differentiation, hypertension, and pro-BNP. Compared to the normal group, patients with transient elevation of CA-125 had significantly correlated transient elevation of pro-BNP $(\mathrm{p}=0.00035)$ (Table 2 , Figure 1B). There were no significant differences within other data with transient elevation of serum CA-125 in post-operative patients. All of the tuberculosis patients' postoperative CA-125 levels were normal.

\section{Cancer antigen 125 status and pattern of disease progression survival in non-small cell lung cancer patients}

Within a median follow-up period of 23 months (range 4-34 months), 42 patients had died or had cancer-recurring incidents. By univariate analysis, comparison of disease progression survival (DFS) between the two groups (CA-125 elevated and not elevated in the early postoperated patients) did not reach statistically significant levels (MST: 31.0 vs. 31.0 months, $\mathrm{p}=0.646$ ) (Figure 2). The factor influencing DFS in the univariate analysis was stage $(95 \% \mathrm{CI} 1.539-5.632 ; \mathrm{HR}=2.944)$ (Table 3).

\section{DISCUSSION}

CA-125, a high molecular weight glycoprotein determinant recognized by murine monoclonal antibody (OC125), is a tumor marker for ovarian cancer, and is usually used to monitor the clinical course of patients with advanced ovarian cancer ${ }^{1,9}$.

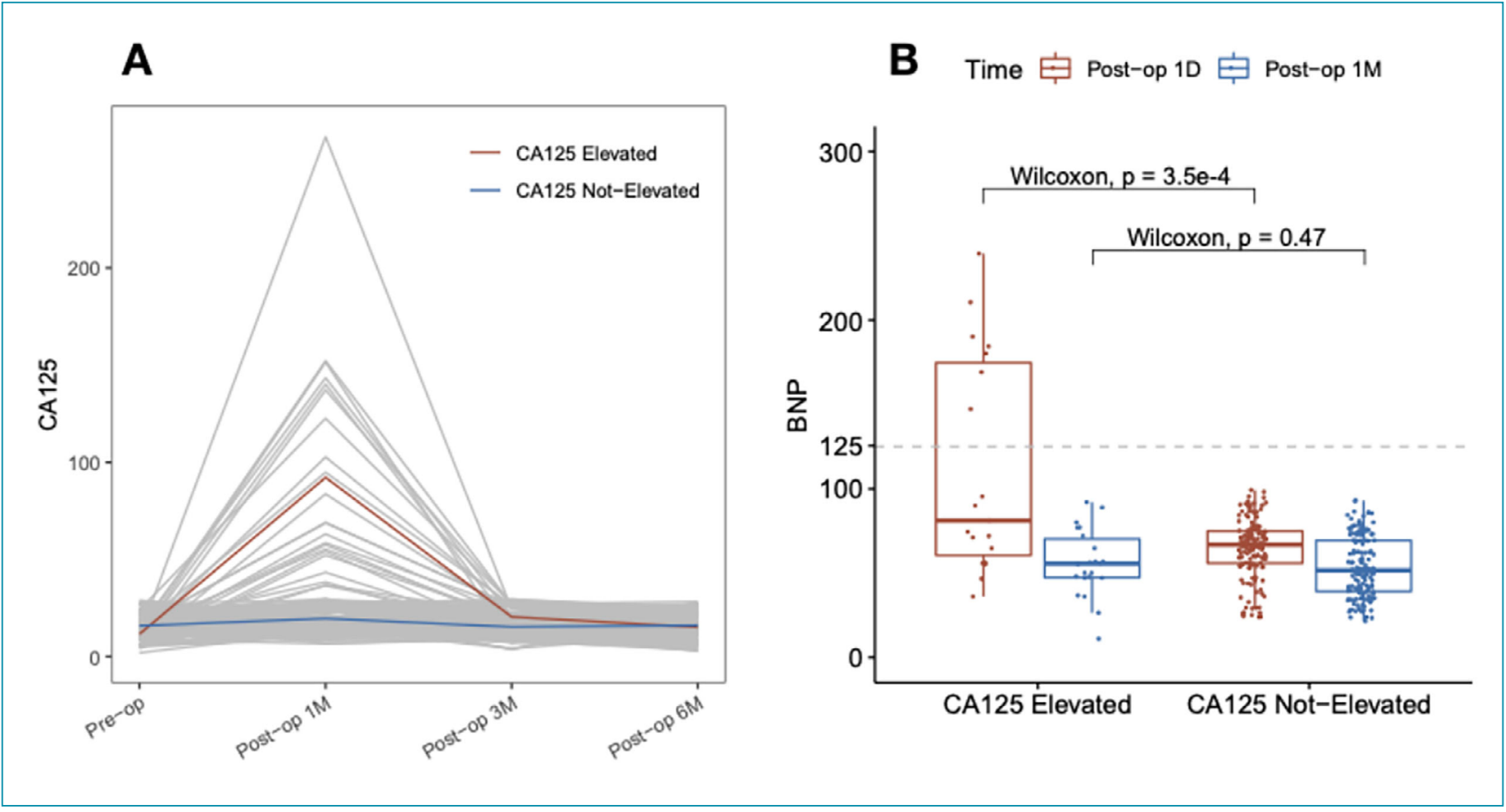

Figure 1. (A) Serum CA125 levels from pre-operation to 6 months post-operation in all 181 NSCLC patients; (B) boxplot showing the comparison of pro-BNP between CA125 elevated and normal group. 
Several studies have shown that high levels of preoperative serum CA-125 were significantly correlated with poor prognosis in NSCLC ${ }^{17}$. However, the correlation of postoperative CA-125 level and prognosis in lung cancer patients remains elusive. But some other studies found that the prognostic values of CA- 125 for NSCLC are limited ${ }^{11}$. Therefore, the prognostic effect of CA-125 remains to be further studied.

In this study, we noticed a group of NSCLC patients presented transient elevation of serum CA-125 after surgery, and evaluated the potential of using this phenomenon as a prognostic biomarker. It was also found that serum CA-125 was decreased to normal level three months after surgery. By univariate analysis, transient elevation of serum CA-125 has not reached statistically significant DFS compared with no transient elevation of serum CA-125 (MST:

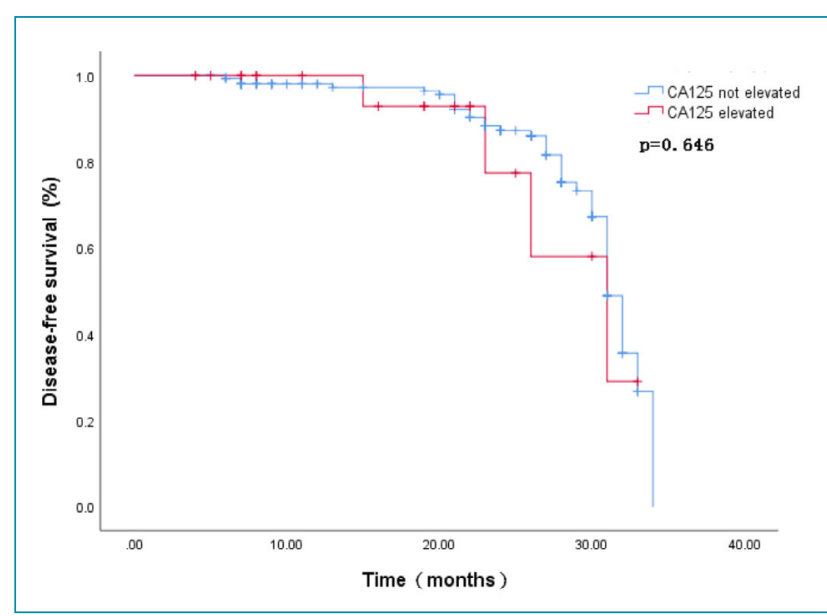

Figure 2. Kaplan-Meier estimates of disease-free survival in the patients with transiently elevated CA125 $(n=22$, red) and in patients without CA125 elevation ( $n=159$, blue)

Table 2. Correlation between cancer antigen 125 elevation/nonelevation and clinicopathological characteristics.

\begin{tabular}{|c|c|c|c|c|}
\hline & & $\begin{array}{l}\text { Cancer antigen } \\
125 \text { elevated }\end{array}$ & Not & $\mathrm{p}$ \\
\hline \multirow{2}{*}{ Age (years) } & $<70$ & 19 & 12 & \multirow{2}{*}{0.400} \\
\hline & $\geq 70$ & 3 & 147 & \\
\hline \multirow{2}{*}{ Gender } & Male & 13 & 84 & \multirow{2}{*}{0.652} \\
\hline & Female & 9 & 75 & \\
\hline \multirow{2}{*}{ Smoking } & Yes & 3 & 48 & \multirow{2}{*}{0.132} \\
\hline & No & 19 & 111 & \\
\hline \multirow{2}{*}{ Operation time (hours) } & $<3$ & 19 & 129 & \multirow{2}{*}{0.770} \\
\hline & $\geq 3$ & 3 & 30 & \\
\hline \multirow[b]{2}{*}{ Surgical approach } & Thoracotomy & 1 & 13 & \multirow[b]{2}{*}{1.000} \\
\hline & $\begin{array}{l}\text { Video-assisted } \\
\text { thoracoscopic surgery }\end{array}$ & 21 & 146 & \\
\hline \multirow[b]{2}{*}{ Type of resection } & Lobectomy/pneumonectomy & 16 & 140 & \multirow[b]{2}{*}{0.090} \\
\hline & $\begin{array}{c}\text { Segmentectomy/wedge } \\
\text { resection }\end{array}$ & 6 & 19 & \\
\hline \multirow{2}{*}{ Tumor location } & Upper lobe & 14 & 93 & \multirow{2}{*}{0.818} \\
\hline & Middle lobe/low lobe & 8 & 65 & \\
\hline \multirow{2}{*}{ Hypertension } & Yes & 2 & 35 & \multirow{2}{*}{0.257} \\
\hline & No & 20 & 124 & \\
\hline \multirow{2}{*}{ Postoperative pleural effusion } & Yes & 3 & 24 & \multirow{2}{*}{1.000} \\
\hline & No & 19 & 135 & \\
\hline \multirow{2}{*}{ Stage } & 1 & 16 & 96 & \multirow{2}{*}{0.351} \\
\hline & $\|/\| \|$ & 6 & 63 & \\
\hline \multirow[b]{2}{*}{ Histology } & Adenocarcinoma & 16 & 104 & \multirow[b]{2}{*}{0.632} \\
\hline & $\begin{array}{l}\text { Squamous cell carcinoma/ } \\
\text { Other type }\end{array}$ & 6 & 55 & \\
\hline \multirow{2}{*}{$\begin{array}{l}\text { Pro-brain natriuretic peptide } \\
\text { elevated postoperatively }\end{array}$} & Yes & 10 & 28 & \multirow{2}{*}{$0.00035^{*}$} \\
\hline & No & 12 & 131 & \\
\hline
\end{tabular}

Cancer antigen 125 elevation: serum cancer antigen 125 was transiently elevated in one month after surgery. 
Table 3. Univariate analysis for disease-free survival (DFS) of clinical variables in relation to DFS for non-small cell lung cancer patients

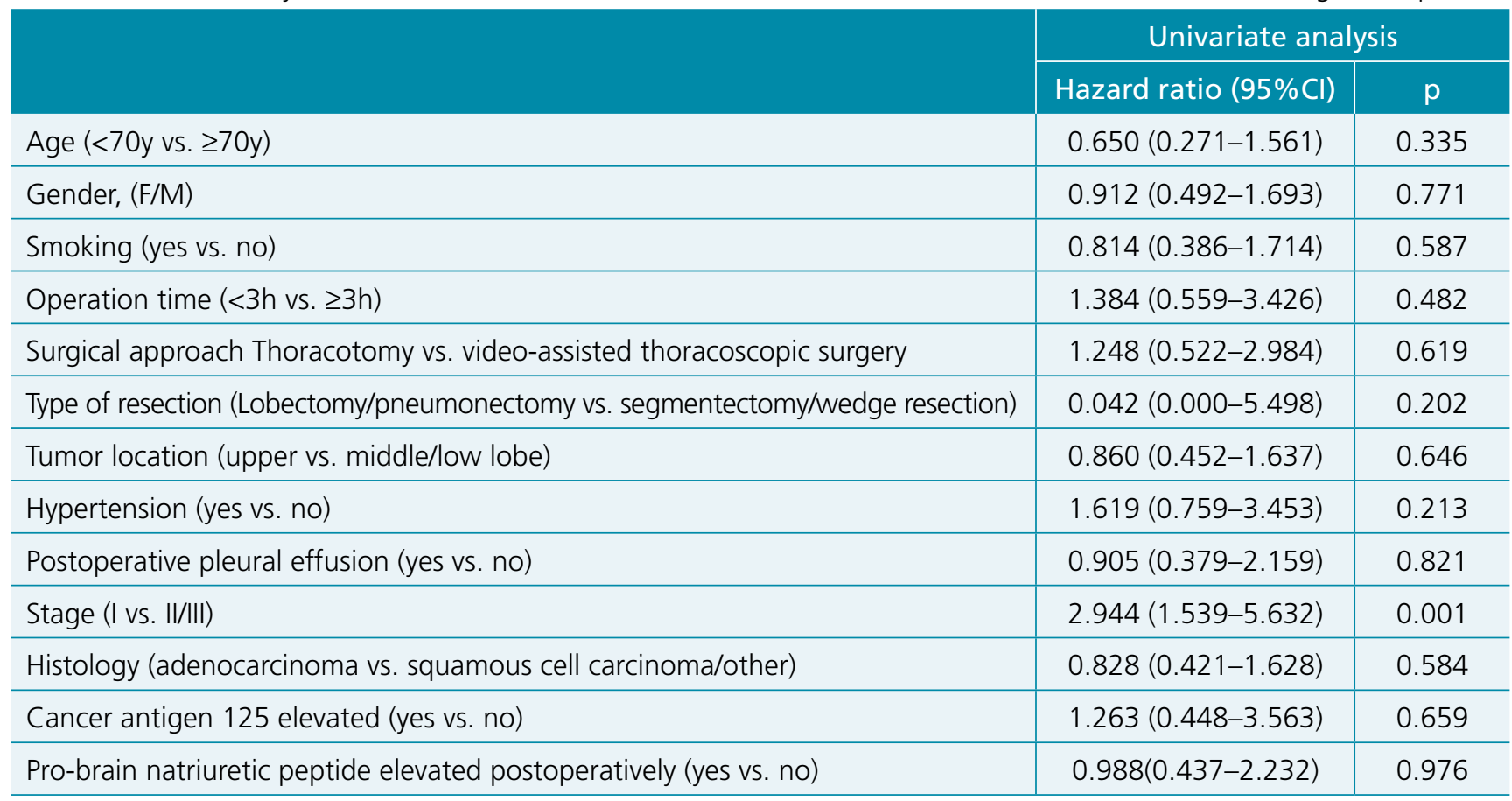

31.0 vs. 31.0 months, $\mathrm{p}=0.646$ ) (Figure 2). Therefore, the condition of transient elevation of serum CA-125 in postoperated patients may not be a prognostic factor for NSCLC after surgery.

The transient elevation of CA-125 levels after surgery is an interesting clinical phenomenon and worth thorough investigation. One explanation is possible tumor cell shedding from tumor tissues during surgery. This notion is supported by studies showing that post-operative circulating tumor DNA (ctDNA) levels in some patients were higher than preoperative levels during the lung cancer surgery ${ }^{19,20}$. However, in our study, transiently elevated CA-125 levels in postoperated patients are not relevant to operation time, surgery type of resection, or worse DFS. Therefore, this hypothesis needs further investigation.

High serum levels of CA-125 have also been reported in other nonmalignant diseases, including heart failure, nephrotic syndrome, liver cirrhosis, tuberculosis, and pelvic inflammatory disease ${ }^{4-10}$. All five patients with tuberculosis had normal levels of CA-125 postoperatively. We cannot confirm the relationship between these nonmalignant diseases and elevation of serum CA-125 postoperatively according to our limited data.

By careful examination of all clinical features with transient CA-125 elevation, we found that pro-BNP levels after surgery were strongly correlated with transient elevation of serum CA-125 in NSCLC patients (Figure 1B) p=0.00035
(Table 2). Several previous studies have shown that both CA-125 and pro-BNP was significantly related with heart function in heart disease patients, and the CA-125 levels were positively correlated with pro-BNP in heart disease patients $^{21-23}$. Pro-BNP is a quantitative biomarker of myocardial function. Postoperative elevation of pro-BNP was correlated with the pulmonary vascular resistance increased in pulmonary resection patients ${ }^{24}$. We speculated that postoperative transient elevation of serum CA-125 is not specifically related to NSCLC, but is more likely to be associated with enhancement of pulmonary vascular resistance after pulmonary surgery.

\section{CONCLUSIONS}

It can be concluded from the above findings that postoperative transient elevation serum CA-125 had no correlation to recommend their use for diagnosis of tumor prognosis and recurrence in NSCLC patients. Transient elevation of CA-125 was found to be associated with pro-BNP level, and further investigation on these features and their clinical relevance is needed.

\section{ACKNOWLEDGEMENTS}

The author thanks Danni Liu and Dr. Yingmei Li for helpful discussion and language editing. 


\section{REFERENCES}

1. Felder M, Kapur A, Gonzalez-Bosquet J, Horibata S, Heintz J, Albrecht R, et al. MUC16 (CA125): tumor biomarker to cancer therapy, a work in progress. Mol Cancer. 2014;13:129. https://doi.org/10.1186/1476-4598-13-129

2. Montagnana $M$, Benati $M$, Danese E. Circulating biomarkers in epithelial ovarian cancer diagnosis: from present to future perspective. Ann Transl Med. 2017;5(13):276. https://doi. org/10.21037/atm.2017.05.13

3. Nazmeen A, Maiti S, Mandal K, Roy SK, Ghosh TK, Sinha NK, et al. Better predictive value of cancer antigen 125 (CA125) as biomarker in ovary and breast tumors and its correlation with the histopathological type/grade of the disease. Med Chem. 2017;13(8):796-804. https:// doi.org/10.2174/1573406413666170424155452

4. Xiao WB, Liu YL. Elevation of serum and ascites cancer antigen 125 levels in patients with liver cirrhosis. J Gastroenterol Hepatol. 2003;18(11):1315-6. https://doi.org/10.1046/j.14401746.2003.03180.x

5. Sevinc A, Buyukberber $S$, Sari R, Turk HM, Ates M. Elevated serum CA-125 levels in patients with nephrotic syndrome-induced ascites. Anticancer Res. 2000;20(2B):1201-3. PMID: 10810422

6. Peng T, Guo L, Xia Q, Yang X. Clinical significance of serum CA-125 in nephrotic syndrome. Clin Lab. 2012;58(1-2):113-5. PMID: 22372353

7. Park ST, Lee SW, Kim MJ, Kang YM, Moon HM, Rhim CC. Clinical characteristics of genital chlamydia infection in pelvic inflammatory disease. BMC Womens Health. 2017;17(1):5. https://doi.org/10.1186/s12905-016-0356-9

8. Llàcer P, Bayés-Genís A, Núñez J. Carbohydrate antigen 125 in heart failure. New era in the monitoring and control of treatment. Med Clin (Barc). 2019;152(7):266-73. https://doi. org/10.1016/j.medcli.2018.08.020

9. Moss EL, Hollingworth J, Reynolds TM. The role of CA-125 in clinical practice. J Clin Pathol. 2005;58(3):308-12. https:// doi.org/10.1136/jcp.2004.018077

10. Du ZX, Liang MM, Sun J, Wang WJ, Liu YH, Yang JH. Clinical significance of serum CA-125, CA19-9 and CEA in pulmonary tuberculosis with and without type 2 diabetes. Tuberculosis (Edinb). 2017;107:104-10. https://doi.org/10.1016/j.tube.2017.08.006

11. Ma S, Shen L, Qian N, Chen K. The prognostic values of CA-125, CA19.9, NSE, AND SCC for stage I NSCLC are limited. Cancer Biomark. 2011;10(3-4):155-62. https://doi. org/10.3233/CBM-2012-0246

12. Pollán $M$, Varela $G$, Torres $A$, de la Torre $M$, Ludeña $M D$, Ortega MD, et al. Clinical value of p53, c-erbB-2, CEA and CA-125 regarding relapse, metastasis and death in resectable non-small cell lung cancer. Int J Cancer. 2003;107(5):781-90. https://doi.org/10.1002/ijc. 11472

13. Cedrés $S$, Nuñez I, Longo $M$, Martinez $P$, Checa $E$, Torrejón $D$, et al. Serum tumor markers CEA, CYFRA21-1, and CA-125 are associated with worse prognosis in advanced non-small-cell lung cancer (NSCLC). Clin Lung Cancer. 2011;12(3):172-9. https://doi.org/10.1016/j.cllc.2011.03.019
14. Lian $S$, Huang $Y$, Yang $H$, Zhao $H$. Serum carbohydrate antigen 12-5 level enhances the prognostic value in primary adenosquamous carcinoma of the lung: a two-institutional experience. Interact Cardiovasc Thorac Surg. 2016;22(4):41924. https://doi.org/10.1093/icvts/ivv369

15. Yu D, Du K, Liu T, Chen G. Prognostic value of tumor markers, NSE, CA-125 and SCC, in operable NSCLC Patients. Int J Mol Sci. 2013;14(6):11145-56. https://doi.org/10.3390/ ijms140611145

16. Isaksson $S$, Jönsson $P$, Monsef $N$, Brunnström $H$, Bendahl PO, Jönsson M, et al. CA 19-9 and CA 125 as potential predictors of disease recurrence in resectable lung adenocarcinoma. PLoS One. 2017;12(10):e0186284. https://doi.org/10.1371/ journal.pone.0186284

17. Ying L, Wu J, Zhang D, Li Z, Li D, Pan X, et al. Preoperative serum CA-125 is an independent predictor for prognosis in operable patients with non-small cell lung cancer. Neoplasma. 2015;62(4):602-9. https://doi.org/10.4149/ neo_2015_072

18. Nuñez $G R$, Ito $C$, Del Giglio A. Increased serum CA-125 levels in patients with lung cancer post thoracotomy. South Med J. 2009;102(4):427-8. https://doi.org/10.1097/ SMJ.0b013e31819b9a8f

19. Bayarri-Lara C, Ortega FG, Cueto Ladrón de Guevara A, Puche JL, Ruiz Zafra J, de Miguel-Pérez D, et al. Circulating tumor cells identify early recurrence in patients with non-small cell lung cancer undergoing radical resection. PLoS One. 2016;11(2):e0148659. https://doi.org/10.1371/journal. pone.0148659

20. Nakano Y, Kitago M, Matsuda S, Nakamura Y, Fujita Y, Imai $S$, et al. KRAS mutations in cell-free DNA from preoperative and postoperative sera as a pancreatic cancer marker: a retrospective study. Br J Cancer. 2018;118(5):662-9. https:// doi.org/10.1038/bjc.2017.479

21. Rong $X$, Yunke Z, Guoping L, Zhenyue C. Clinical and prognostic value of elevated CA-125 levels in patients with coronary heart disease. Herz. 2015;40(4):690-4. https://doi. org/10.1007/s00059-014-4109-y

22. Chen $Y X$, Wang $X Q$, Fang $C F$, Wang JF, Tang $L$ J. Value of BNP and tumour marker $C A-125$ in patients with heart failure. Acta Cardiol. 2008;63(4):501-6. https://doi.org/10.2143/ AC.63.4.2033050

23. Karaca O, Guler GB, Guler E, Gunes HM, Alizade E, Agus $\mathrm{HZ}$, et al. Serum carbohydrate antigen 125 levels in nonischemic dilated cardiomyopathy: a useful biomarker for prognosis and functional mitral regurgitation. Congest Heart Fail. 2012;18(3):144-50. https://doi.org/10.1111/j.17517133.2011.00260.x

24. Tayama K, Takamori S, Mitsuoka M, Hayashi A, Tamura K, Mifune $\mathrm{H}$, et al. Natriuretic peptides after pulmonary resection. Ann Thorac Surg. 2002;73(5):1582-6. https://doi.org/10.1016/ s0003-4975(02)03417-3 